\title{
In-Pipe Turbine Design for Turbo Solenoid Valve System
}

\author{
Y.Mutlu ${ }^{1}$, M.Çakan ${ }^{1}$ \\ ${ }^{1}$ (Departmentof Mechanical Engineering, Istanbul Technical University, Turkey)
}

\begin{abstract}
This paper is about the design of a turbine for a turbo-solenoid system which is an innovative patented system. Turbo solenoid system is a newly developed, self-sufficient system, which can be used for flow control automation. Thanks to its self-sufficiency, flow control can be performed without any cables for energy supplying or control.In a turbo-solenoid system, turbine is certainly the most important element. Therefore the main aim of this paper is, design of a suitable in-pipe turbine for turbo solenoid system by using CFD analysis. In this context, different types of turbines; Darrieus, Gorlov and Lucid ${ }^{\circledR}$ which are suitable for in-pipe applications have been examined. In the CFD analysis, beside turbine type, also the effect of the twisting angle and aerofoil profile on the turbine performance was investigated.As a result of the analysis carried out for same dimension turbines with NACA0018 profile, it is found that Lucid® turbine producesthe highest torque value but also causesthe highest pressure drop in pipe. On the other hand, $10^{\circ}$ twisted Gorlov turbine produce $30.35 \%$ less torque than Lucid® turbine but against that, its pressure drop penalty isalso $54.94 \%$ less.

The effect of the aerofoil profile was investigated for two Darrieus turbine profiles (NACA0021and NACA0015).As a result of this comparison, it is revealed that NACA0021aerofoil produces $1.89 \%$ less torque compared to NACA0018 but causes 2.89\% more pressure drop, and NACA0015aerofoil produces $5.24 \%$ higher torque compared to NACA0018 but causes $1.35 \%$ more pressure drop.

On the investigation on blade twisting angle effect, $20^{\circ}$ twisted Gorlov turbine has been studied. As a result, it is found that $20^{\circ}$ twisted Gorlov turbine produces $18.13 \%$ higher torque and $4.12 \%$ less pressure drop than $10^{\circ}$ twisted Gorlov turbine. Finally $20^{\circ}$ twisted Gorlov turbine with NACA0015 aerofoil has been studied and it is revealed that only by \%4.47 less torque production and \%54.40 less pressure drop, compared to Lucid® turbine, $20^{\circ}$ twisted Gorlov turbine with NACA0015 aerofoil shows the best performancewith respect to all studied turbines.
\end{abstract}

Keywords: CFD, Flow Control, In-Pipe Turbine, Process Automation, Self-Sufficient Sysytem, Solenoid Valve

\section{Introduction}

Fluid control technology has many different applications in industry, service sector and domestic usage. In 2017, the worldwide valve industry market potentialis expected to reach $\$ 80$ billion. This value is estimated to be $\$ 98.5$ billion by 2019 [1]. On the other hand, with the spread of concepts such as the industrial 4.0 revolution andIoT, the interest and need for intelligent systems is increasing day by day. In this respect, especially with the current user trends two issues have gained importance: energy efficiency and self-sufficiency

Especially in regions where it is difficult to transmit the electric energy,supplying energy for flow automation equipment is an important issue. Cable networks established for the energy supply and control of flow automation equipment in facilities like international oil and natural gas transportation lines, large power plants, petrochemical plants and petroleum refineries bring serious installation and repair/maintenance costs to the enterprises. In such facilities failure of flow control equipment can sometimes lead to adverse events. Due to this reason, repairs and maintenances are done continuously to ensure that these systems work continuously without any problem. Especially in areas with the risk of explosion, these costs are increasing due to the special equipmentused, and failures that can cause greater disasters.

This numerical study is about the control of fluid control equipment with establishment of a locally self-sufficient system by generating energy with the aid of the fluid to be controlled. Thanks to this system, process control automation will become much easier and especially in big pipe networkswithout any cabling system, only by using wireless energy and wireless communication processes, fluid control will be made possible.

In turbo-solenoid systems, a rotational motion of a turbine is achieved by using fluid flow. Through this motion an electrical generator is operated. Thus, the solenoid valve is energized by the generated electricity.To keep energy in constant level and to give the system an opportunity to function in every situation, an accumulator has also been used.

Briefly, the working principle of a turbo solenoid valve is as follows; Fluid flow rotates the turbine blades, turbine blades rotatethe generator and the generator generates alternative current. By using a rectifier and regulator circuits, constant direct current is produced. This DC supplies the necessary energy for loading the accumulator and control system. The energy stored in the accumulator may also be used to energize the communication system when the valve is in halt.

DOI: 10.9790/1684-1402073341 $\quad$ www.iosrjournals.org $33 \mid$ Page


The measurements made on a latching solenoid valve indicate that $5 \mathrm{~W}$ power is sufficient for opening and closing the valve every 10 seconds. One of the most important problems of self-sufficient systems is energy supply and the equipment that are used to generate energy.

As it is known, turbine is the main elementfor transforming the fluid flow energy to mechanical energy. With respect to the rotational axis of the turbine and fluid direction, it is possible to classify turbines in two groups: 1) Axial Flow Turbines, 2) Cross Flow Turbines. In axial flow turbines, the direction of the rotation axis of the turbine is parallel to the main fluid flow direction. In cross flow turbines, the fluid flow direction is perpendicular to the rotation axis of the turbine in such it is not needed that the direction of the rotation axis change relative to the flow direction and this is an advantage of cross flow turbines with respect to axial flow turbines. However, design and prediction of hydrodynamic behavior of such turbines is very difficult [2]. On the other hand, in cross flow turbines because of flow structure, turbine aerofoils are exposedto different loads. In these turbines, during each turn, variable loads affect the turbine and this may cause material fatigue. The intensity of this mechanical loads indicates the lifetime of the turbines. Due to this, material fatigue analysis constitutes a very important research aspect in these type of turbines. Therefore, during designing of cross flow turbines, to mitigate the adverse effects of material fatigue, reduction of maximum, minimum and mean load differences should be considered.

Generally cross flow turbines have two important advantages over axial flow turbines: 1- They can be coupled directly to the generator (without using intermediate gear mechanism), 2- They are easy to install. On the other hand, hydrodynamics of cross-flow turbines are very complex due to three different reasons, which cause uncertainty, complex turbulence and flow separation: 1-Changing of angle of attack during each turn. 2Influence of aerofoil fluctuations on each other, 3- Influence of connecting arms on flow field [3].In cross flow turbines, at low rotational speeds, change of angle of attack effectively alters turbine performance and causes static and dynamic stalls [4]. On the other hand, the performance of the turbine at high speeds is influenced by flow turbulence, turbulence created by the aerofoils, and interactions caused by both of them [5]. Also, as the rotational speed increases, the drag effect of the connecting arms increases and the total generated torque decreases [6].In this study, it is planned to use cross flow turbine because it is more suitable for the considered turbo-solenoid system and it is simpler for mass production in the future. Also it should be kept in mind that the main aim of this system is not to generate electricity;but to produce sufficient energy for turbo solenoid valve system with minimum pressure loss.

The 3 cross flow turbines analyzed and compared to each other in this study are Darrieus Turbine [7], Gorlov Turbine [8] and Lucid® Turbine [9] (Fig. 1).

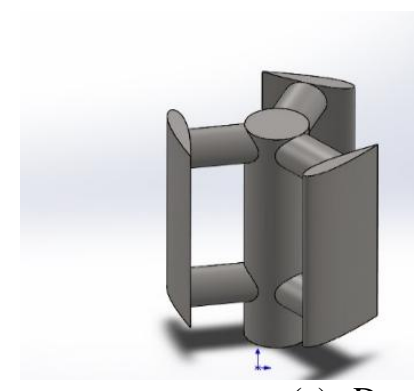

(a) Darrieus

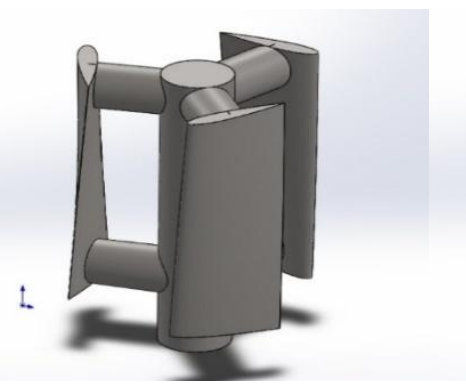

(b) Gorlov

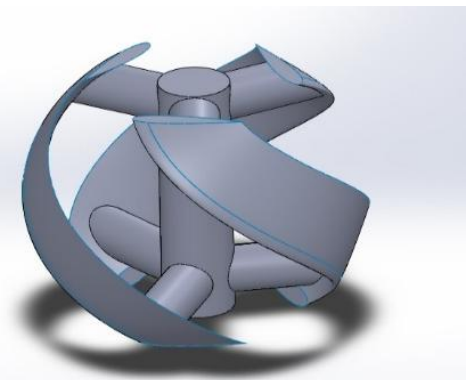

(c) Lucid®

Fig. 1. Cross-flow turbines to be analyzed.

\section{Performance Criteria in Cross Flow Turbines}

As it seen in Fig.2, in cross flow turbines, the flow velocity changes continuously relative to the orientation of the turbine.

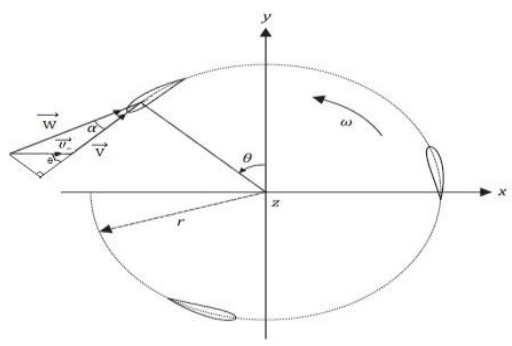

Fig.2. Aerofoil velocity triangle.

By using velocity triangle trigonometry, relative velocity $(\mathrm{W})$ can be expressed in terms of flow velocity $\left(U_{\infty}\right)$ and tangential velocity (V) as below: 
$W=\sqrt{\left(\overrightarrow{U_{\infty}} \operatorname{Cos} \theta+\vec{V}\right)^{2}+\left(\overrightarrow{U_{\infty}} \operatorname{Sin} \theta\right)^{2}}$

$W=\sqrt{\overrightarrow{U_{\infty}^{2}} \operatorname{Cos}^{2} \theta+\overrightarrow{V^{2}}+2 \overrightarrow{U_{\infty}} \cdot \vec{V} \cdot \operatorname{Cos} \theta+\overrightarrow{U_{\infty}^{2}} \operatorname{Sin}^{2} \theta}$

$W=\sqrt{\overrightarrow{U_{\infty}^{2}}+\overrightarrow{V^{2}}+2 \overrightarrow{U_{\infty}} \cdot \vec{V} \cdot \operatorname{Cos} \theta}$

where tangential or chord velocity is related to angular velocity with the following relation:

$|\vec{V}|=r . \omega$

Also in the literature, the ratio of tangential velocity to the absolute flow velocity is called "tip speed ratio".

$\lambda=\frac{|\vec{V}|}{\left|\overrightarrow{U_{\infty}}\right|}=\frac{r \cdot \omega}{U_{\infty}}$

If we substitutethe velocity parameters in equation 3 with the tip speed ratio:

$W=U_{\infty} \sqrt{1+\lambda^{2}+2 \lambda \cdot \operatorname{Cos} \theta}$

$U_{\infty}$ velocity variesalong the diameter of the pipe in which the turbine is installed and is a function of turbine height $h$.

$\bar{W}=\frac{1}{2 \pi} \int_{0}^{2 \pi} W d \theta$

On the other hand, angle of attack is a function of $\theta$ angle:

$\alpha=\arctan \left(\frac{U_{\infty} \operatorname{Sin} \theta}{U_{\infty} \operatorname{Cos} \theta+V}\right)$

$\alpha=\arctan \left(\frac{\sin \theta}{\operatorname{Cos} \theta+\lambda}\right)$

If blades have any attack angle $(\beta)$ at $\theta=0$ point, Equation 9 is written as below:

$\alpha=\arctan \left(\frac{\operatorname{Sin} \theta}{\operatorname{Cos} \theta+\lambda}\right)-\beta$

In Fig.3, drag and lift forces are shown on a cross flow turbine aerofoil. The normal and tangential components of these forces are called normal force $\left(\mathrm{F}_{\mathrm{n}}\right)$ and tangential force $\left(\mathrm{F}_{\mathrm{t}}\right)$ respectively.

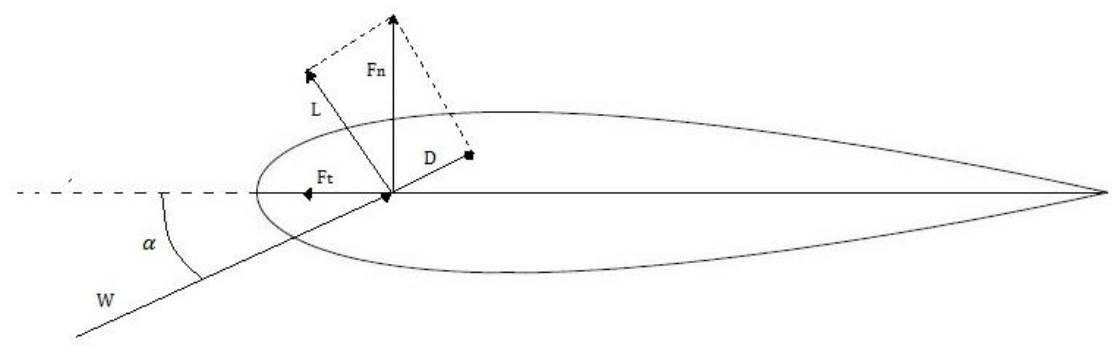

Fig. 3. Forces on cross flow turbine aerofoil.

Two of the terms which are used to calculate the performance of a turbine is tangential force coefficient $\left(C_{t}\right)$ and normal force coefficient $\left(C_{n}\right)$. Tangential force coefficient depicts the difference between the tangential 
components of lift and drag forces. Normal force coefficientstands for the difference between the normal components of lift and drag forces.

$$
\begin{aligned}
& \mathrm{Ct}=\mathrm{Cl} \operatorname{Sin} \alpha-\mathrm{Cd} \operatorname{Cos} \alpha \\
& \mathrm{Cn}=\mathrm{Cl} \operatorname{Cos} \alpha+\mathrm{Cd} \operatorname{Sin} \alpha
\end{aligned}
$$

In this case, the net tangential and normal forces can be defined as follows:

$F_{t}=C_{t} \frac{1}{2} \rho c h W^{2}$

$F_{n}=C_{n} \frac{1}{2} \rho c h W^{2}$

In the above equations $\mathrm{c}$ is the chord length, $\rho$ is fluid density and $\mathrm{h}$ is turbine height. $\mathrm{F}_{\mathrm{t}}$ varies with respect to $(\theta)$ turning angle. So, mean tangential force for one aerofoil can be calculated as follow:

$\overline{F_{t}}=\frac{1}{2 \pi} \int_{0}^{2 \pi} F_{t}(\theta) d \theta$

In this case, for a turbine with $\mathrm{N}$ aerofoil, torque can be calculated as below:

$M=N \cdot \overline{F_{t}} \cdot r$

Also the total power can be calculated as follows:

$$
\mathrm{P}=\mathrm{M} . \omega
$$

Tip speed ratio (Eq. 5) expresses the ratio of tangential flow velocity to the main flow velocity. When the tip speed ratio decreases, friction forces become enforced and when it increases loads on aerofoils become higher. High tip speed ratio causes a high level of noise in wind turbines. As the tip speed ratio increases, stronger aerofoils need to be used due to the increase in centrifugal forces.

One of the most important performance criteria of turbines is the power ratio. By using the Buckingham $\pi$ theorem, the dimensionless power ratio can be obtained as shown in equation 18.

$C_{p}=\frac{P}{\rho \frac{U_{\alpha}^{3}}{2} D . h}$

The power ratio is the ratio of power available in the flow to the earned power. This equation is same as efficiency, so it has a value between 0 and 1 .

\section{Numerical Approach}

The characteristics of the turbines, which will be subjected to CFD analysis are given in Table 1.

Table 1. Turbine characteristics.

\begin{tabular}{|l|l|l|l|}
\hline Characteristic & Darrieus & Gorlov & Lucid® \\
\hline Number of Aerofoil & 3 & 3 & 3 \\
\hline Attack Angle & $0^{\circ}$ & $0^{\circ}$ & $0^{\circ}$ \\
\hline Turbine Height (h) & $32 \mathrm{~mm}$ & $32 \mathrm{~mm}$ & $37 \mathrm{~mm}$ \\
\hline Turbine Diameter (D) & $30 \mathrm{~mm}$ & $30 \mathrm{~mm}$ & $45 \mathrm{~mm}^{*}$ \\
\hline Aerofoil Profile & NACA0018 & NACA0018 & NACA0018 \\
\hline MainAxis Diameter & $10 \mathrm{~mm}$ & $10 \mathrm{~mm}$ & $10 \mathrm{~mm}$ \\
\hline Support Bars Diameter & $7 \mathrm{~mm}$ & $7 \mathrm{~mm}$ & $7 \mathrm{~mm}$ \\
\hline Chord Length & $15 \mathrm{~mm}$ & $15 \mathrm{~mm}$ & $15 \mathrm{~mm}$ \\
\hline Twist Angle & $0^{\circ}$ & $10^{\circ} / 20^{\circ}$ & $120^{\circ}$ \\
\hline
\end{tabular}

* diameter of the sphere

Because the turbo solenoid is a low energy consuming system and its sole aim is to trigger the latching solenoid valve, the solenoid turbine, which will be used in this system must be able to generate the required energy with minimum pressure drop.In this design study, the FLUENT software package was used to solve the 
flow equations.Mesh generation is one of the most crucial phases of the CFD analysis. Before the general analyses, the mesh sensitivity issue was checked. As a result,a mesh grid with 8 million nodes was found to be satisfactory. For flow analysis in a rotating frame, FLUENT's MRF (Multiple Rotating Reference Frame) solution methodology was utilized (Fig. 4).

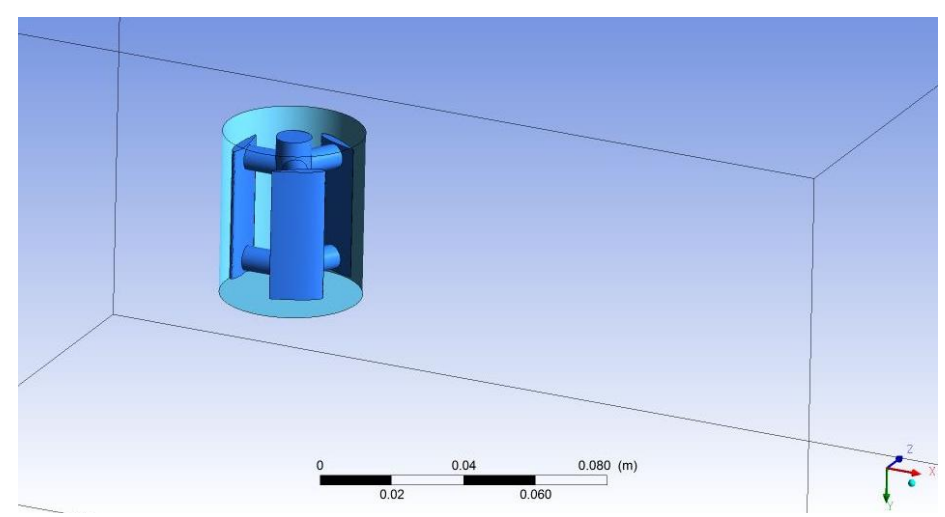

Fig.4. MRF analysing method.

A more precise solution was achieved by creating a higher quality mesh in the framed area (Fig.5). This high quality mesh frame was separated from other zones by interface boundary condition.

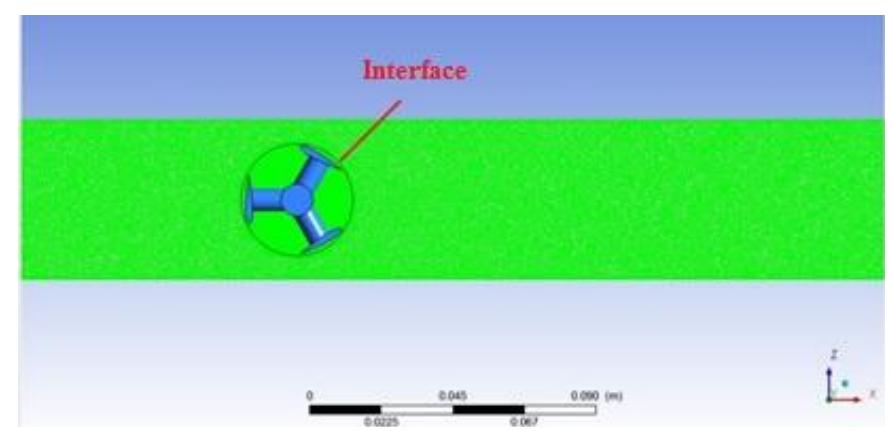

Fig.5. Interface boundary condition.

During the analysis, the cylinder frame volume was rotated around the axis to force the solution to be produced for a rotating turbine. In this way, the analysis was carried out by placing the turbine at different rotational angles in the cylinder. Due to the use of 3 aerofoil turbines in the designs, 12 analyses were carried out for each design by turning the turbine by 10 degrees.

One of the most important factors in CFD analysis is the turbulence closure. Since all the flows analysed in this design study are pipe flows and the Reynolds number is much higher than 2300, the flow is fully turbulent and the standard k- $\varepsilon$ model is chosen as the solution model.Since the near wall modelling is more curicial in turbulence solution, "Enhanced Wall Treatments", which analyze near wall modelling, is preferred.Therefore $\mathrm{y}^{+}$was chosen to be $<5$ (Fig.6).

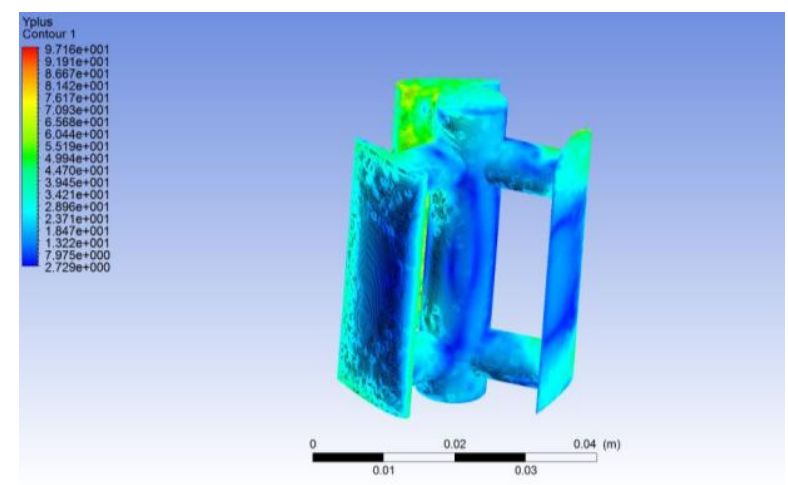

Fig.6. Turbine $\mathrm{y}^{+}$value. 
Four different boundary conditions were used in this study. "Velocity inlet" at the pipeentry surface, "Outflow" for the fluid outlet surface, "Interface" for the surface between the rotating cylinder mesh and the flowing flow mesh and "Wall" conditions were used for pipe surface (Fig.7).

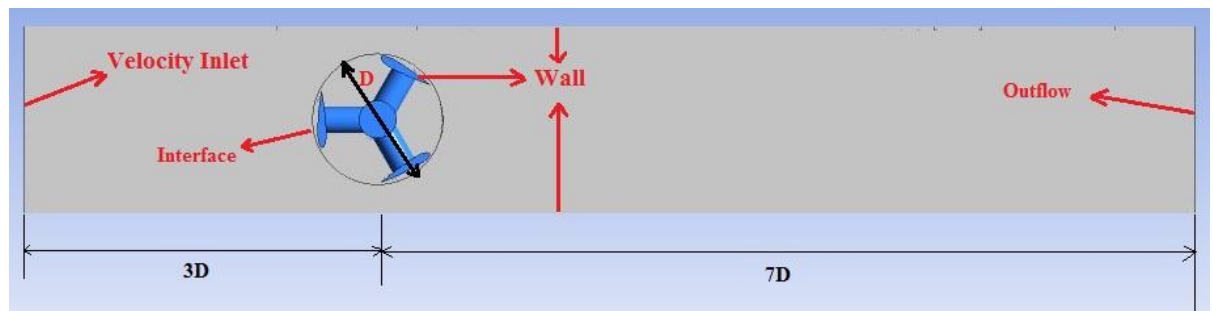

Fig.7. Boundary conditions.

In the analyses, $3 \mathrm{~m} / \mathrm{s}$ inlet velocity and $157 \mathrm{rad} / \mathrm{s}$ angular velocity have been assumed.

\section{CFDResults}

In this study, three different factors were investigated: 1- Turbine type effect, 2- Effect of the aerofoil profile 3- Aerofoil twist angle effect.

As already mentioned, in order to study the turbine type effect, Darrieus, $10^{\circ}$ twisted Gorlov and Lucid® turbines with NACA0018 aerofoil profiles have been analyzed. Analysis of NACA0015 and NACA0021 Darrieus turbines were conducted to investigate the effect of the aerofoil profile. Finally, an analysis of $20^{\circ}$ twisted Gorlov turbine with NACA 0018 profile was carried out to investigate the twisting angle effect.

It is very important that the torque generated by the turbine in different positions and the pressure losses do not vary drastically. When the turbine is rotating, torque changes at different angles will lead to load changes and as a result increase the fatigue rate of the materials. Also, the difference in pressure drop caused by the turbine during rotation at different angles will cause the increase of hydrodynamic instabilities. In this context, as well as comparing the turbines with one another, the moments they produce and the pressure loss they create, different standard deviation of these two values will be taken into consideration. Table 2 and Table 3 present the mean moment produced by the different types of analyzed turbines and the average pressure loss they produce, along with standard deviations sorted from bigger to smaller.

Table 2. Mean torque values.

\begin{tabular}{|l|l|l|}
\hline Turbine Type & Mean Torque [N.m] & Standard Deviation \\
\hline Lucid® NACA0018 & 0.04585555 & 0.01301084 \\
\hline Gorlov20 - NACA0018 & 0.037727075 & 0.017828624 \\
\hline Darrieus-NACA0015 & 0.03691366 & 0.021101953 \\
\hline Darrieus-NACA0018 & 0.035074661 & 0.02272119 \\
\hline Darrieus-NACA0021 & 0.034413096 & 0.01897851 \\
\hline Gorlov10-NACA0018 & 0.031936833 & 0.021246339 \\
\hline
\end{tabular}

Table 3. Mean pressure loss values.

\begin{tabular}{|l|l|l|}
\hline Turbine Type & Pressure Loss [Pa] & Standard Deviation \\
\hline Lucid@-NACA0018 & 15232.74 & 1006.381761 \\
\hline Darrieus-NACA0021 & 7803.24 & 744.4617601 \\
\hline Darrieus-NACA0015 & 7686.17 & 643.5457607 \\
\hline Darrieus-NACA0018 & 7583.84 & 772.2046954 \\
\hline Gorlov10-NACA018 & 6864.42 & 412.1692811 \\
\hline Gorlov20-NACA0018 & 6581.94 & 693.8110904 \\
\hline
\end{tabular}

When the results are examined, it is observed that the highest torque production with the lowest standard deviation is in the Lucid® turbine. Due to the structure of the Lucid® turbine, it is expected that the average moment deviation in such turbines is low. However, it seems that pressure drop in this type of turbine is very high (Table 3). As it is mentioned, the main aim of this study is to select a turbine, which produces the 
power required for the turbo solenoid system with minimum pressure drop but it seems that the Lucid® turbine is not very suitable for this target because it causes a pressure drop about $100 \%$ higher compared to other turbine types.

When the other turbine types are examined, it is observed that the $20^{\circ}$ twisted Gorlov turbine with NACA0018 aerofoil profile has the second highest torque production with the lowest pressure drop. Also the results of the analysis of Darrieus turbine which was carried out to examine the effect of the aerofoil profile showed that the NACA0015 profile gave the best result in terms of moment production. The Darrieus turbine with NACA0015 profile has $1.35 \%$ increase and $1.5 \%$ decrease in pressure drop against $5.24 \%$ and $7.27 \%$ torque increase when compared to NACA0018 and NACA0021 profiles respectively. So, it was concluded that the $20^{\circ}$ twisted Gorlov turbine with NACA0015 profile could give the best result and the analysis of this turbine was carried out under similar conditions.

For a comparison, the average torque produced and the average pressure drop occurred are compared in crosswise tables (Table 4 and Table 5). In these two tables, each cell shows the ratio of the vertical turbine type value to the horizontal turbine type value and specified that the produced torque or created pressure drop of vertical column turbine is higher or lower than the turbine in horizontal column in percentage.

Table 4. Average torque ratios.

\begin{tabular}{|l|l|l|l|l|l|l|l|}
\hline Turbine Type & $\begin{array}{l}\text { Lucid } \\
\text { NACA0018 }\end{array}$ & $\begin{array}{l}\text { Darrieus- } \\
\text { NACA0018 }\end{array}$ & $\begin{array}{l}\text { Darrieus- } \\
\text { NACA0015 }\end{array}$ & $\begin{array}{l}\text { Darrieus- } \\
\text { NACA0021 }\end{array}$ & $\begin{array}{l}\text { Gorlov10- } \\
\text { NACA0018 }\end{array}$ & $\begin{array}{l}\text { Gorlov20- } \\
\text { NACA0018 }\end{array}$ & $\begin{array}{l}\text { Gorlov20- } \\
\text { NACA0015 }\end{array}$ \\
\hline $\begin{array}{l}\text { Lucid } ₫-~ \\
\text { NACA0018 }\end{array}$ & $*$ & $30.74 \%$ & $24.22 \%$ & $33.25 \%$ & $43.58 \%$ & $21.55 \%$ & $4.68 \%$ \\
\hline $\begin{array}{l}\text { Darrieus- } \\
\text { NACA0018 }\end{array}$ & $-23.51 \%$ & $*$ & $-4.98 \%$ & $1.92 \%$ & $9.83 \%$ & $-7.03 \%$ & $-19.93 \%$ \\
\hline $\begin{array}{l}\text { Darrieus- } \\
\text { NACA0015 }\end{array}$ & $-19.50 \%$ & $5.24 \%$ & $*$ & $7.27 \%$ & $15.58 \%$ & $-2.16 \%$ & $-15.74 \%$ \\
\hline $\begin{array}{l}\text { Darrieus- } \\
\text { NACA0021 }\end{array}$ & $-24.95 \%$ & $-1.89 \%$ & $-6.77 \%$ & $*$ & $7.75 \%$ & $-8.78 \%$ & $-21.44 \%$ \\
\hline $\begin{array}{l}\text { Gorlov10- } \\
\text { NACA0018 }\end{array}$ & $-30.35 \%$ & $-8.95 \%$ & $-13.48 \%$ & $-7.20 \%$ & $*$ & $-15.35 \%$ & $-27.10 \%$ \\
\hline $\begin{array}{l}\text { Gorlov20- } \\
\text { NACA0018 }\end{array}$ & $-17.73 \%$ & $7.56 \%$ & $2.20 \%$ & $9.63 \%$ & $18.13 \%$ & $*$ & $-13.88 \%$ \\
\hline $\begin{array}{l}\text { Gorlov 20- } \\
\text { NACA0015 }\end{array}$ & $-4.47 \%$ & $24.90 \%$ & $18.67 \%$ & $27.30 \%$ & $37.17 \%$ & $16.12 \%$ & $*$ \\
\hline
\end{tabular}

Table 5. Average pressure drop ratios.

\begin{tabular}{|l|l|l|l|l|l|l|l|}
\hline $\begin{array}{l}\text { Turbine } \\
\text { Type }\end{array}$ & $\begin{array}{l}\text { Lucid }{ }^{\circledR}- \\
\text { NACA0018 }\end{array}$ & $\begin{array}{l}\text { Darrieus- } \\
\text { NACA0018 }\end{array}$ & $\begin{array}{l}\text { Darrieus- } \\
\text { NACA0015 }\end{array}$ & $\begin{array}{l}\text { Darrieus- } \\
\text { NACA0021 }\end{array}$ & $\begin{array}{l}\text { Gorlov10- } \\
\text { NACA0018 }\end{array}$ & $\begin{array}{l}\text { Gorlov20- } \\
\text { NACA0018 }\end{array}$ & $\begin{array}{l}\text { Gorlov20- } \\
\text { NACA0015 }\end{array}$ \\
\hline $\begin{array}{l}\text { Lucid }{ }^{\circledR} \\
\text { NACA0018 }\end{array}$ & $*$ & $100.86 \%$ & $98.18 \%$ & $95.21 \%$ & $121.91 \%$ & $131.43 \%$ & $119.30 \%$ \\
\hline $\begin{array}{l}\text { Darrieus- } \\
\text { NACA0018 }\end{array}$ & $-50.21 \%$ & $*$ & $-1.33 \%$ & $-2.81 \%$ & $10.48 \%$ & $15.22 \%$ & $9.18 \%$ \\
\hline $\begin{array}{l}\text { Darrieus- } \\
\text { NACA0015 }\end{array}$ & $-49.54 \%$ & $1.35 \%$ & $*$ & $-1.50 \%$ & $11.97 \%$ & $16.78 \%$ & $10.65 \%$ \\
\hline $\begin{array}{l}\text { Darrieus- } \\
\text { NACA0021 }\end{array}$ & $-48.77 \%$ & $2.89 \%$ & $1.52 \%$ & $*$ & $13.68 \%$ & $18.56 \%$ & $12.34 \%$ \\
\hline $\begin{array}{l}\text { Gorlov10- } \\
\text { NACA0018 }\end{array}$ & $-54.94 \%$ & $-9.49 \%$ & $-10.69 \%$ & $-12.03 \%$ & $*$ & $4.29 \%$ & $-1.18 \%$ \\
\hline $\begin{array}{l}\text { Gorlov20- } \\
\text { NACA0018 }\end{array}$ & $-56.79 \%$ & $-13.21 \%$ & $-14.37 \%$ & $-15.65 \%$ & $-4.12 \%$ & $*$ & $-5.24 \%$ \\
\hline $\begin{array}{l}\text { Gorlov 20- } \\
\text { NACA0015 }\end{array}$ & $-54.40 \%$ & $-8.41 \%$ & $-9.63 \%$ & $-10.98 \%$ & $1.19 \%$ & $5.53 \%$ & $*$ \\
\hline
\end{tabular}

As shown in Table 4, the $20^{\circ}$ twisted Gorlov NACA0015 profile is the second best in terms of turbine moment production. This turbine produces only $4.47 \%$ less torque than the Lucid® turbine with NACA0018 profile. However, as shown in Table 5, it causes $54.4 \%$ less pressure drop than the Lucid ${ }^{\circledR}$ turbine. $20^{\circ}$ twisted Gorlov turbine with NACA0015 profile is ranked 5th in terms of pressure drop. The pressure drop produced by this turbine is $1.19 \%$ higher than the $10^{\circ}$ twisted Gorlov turbine with NACA0018 profile. However, the corresponding momentum is $37.17 \%$ higher. Similarly, $20^{\circ}$ twisted Gorlov turbine with NACA0015 profile creates $5.53 \%$ higher pressure drop than $20^{\circ}$ twisted Gorlov turbine with NACA0018 profile. However, it produces $16.12 \%$ more torque.

Fig. 8 and Fig.9 show the torque produced by all the turbines analyzed and the pressure drop they caused. 


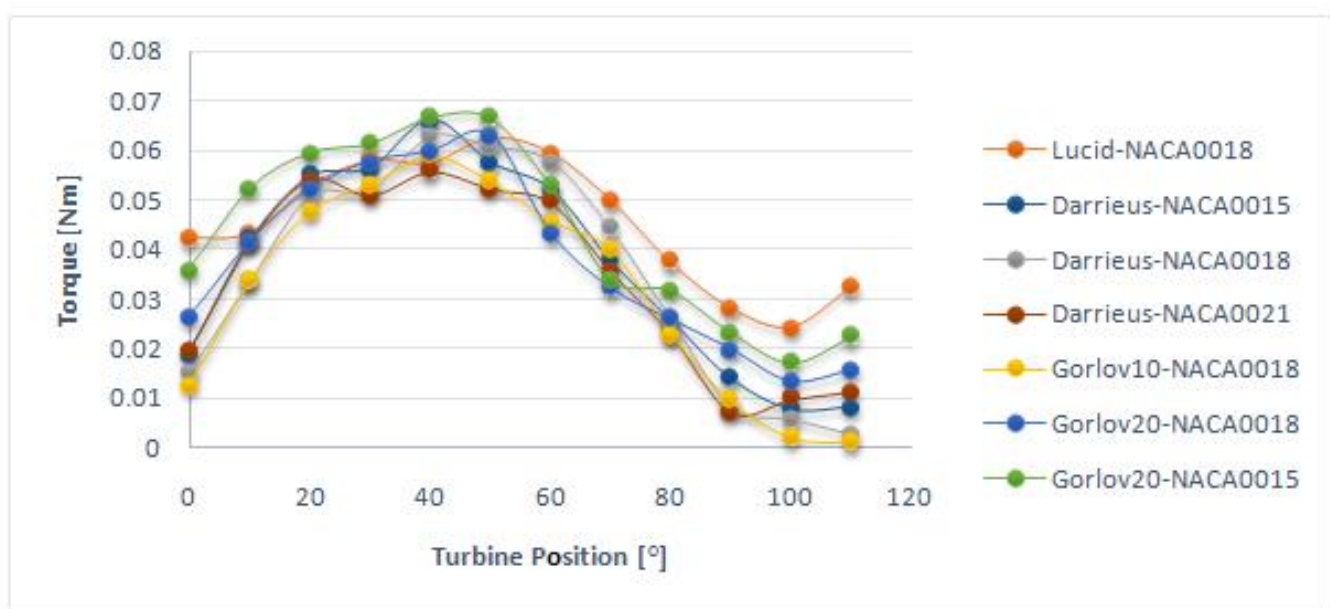

Fig.8. Turbine position-torque variation graph.

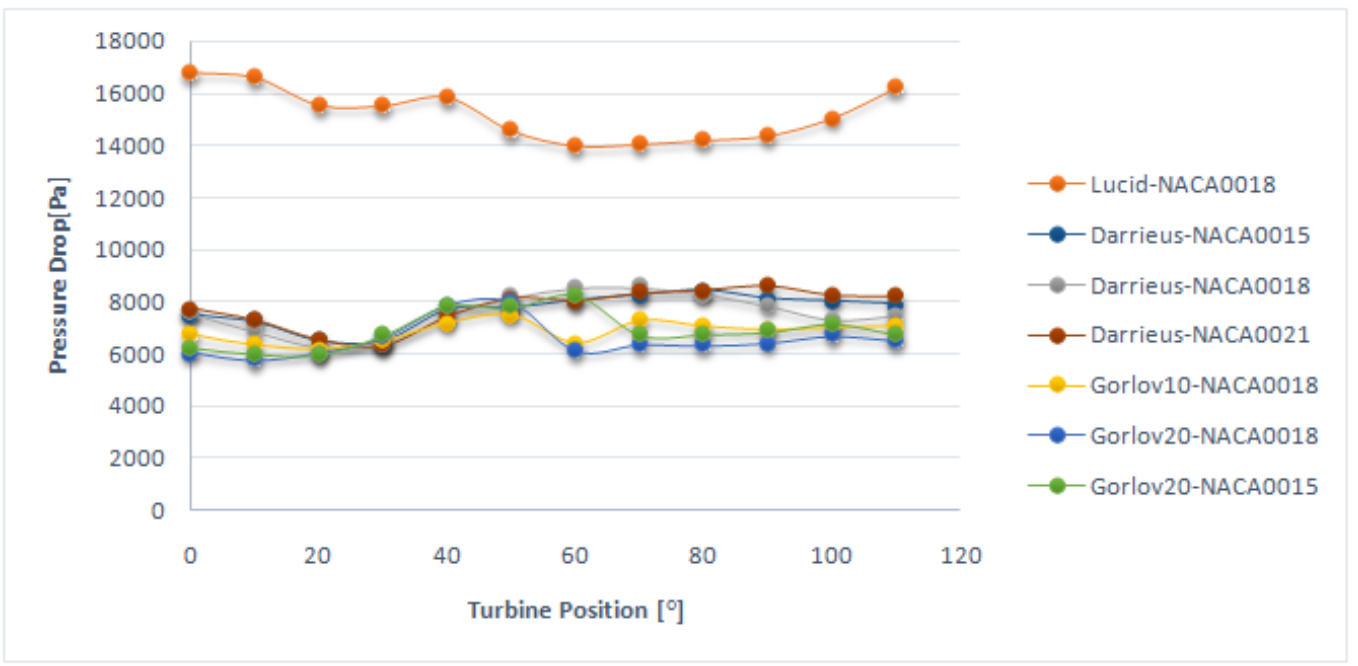

Fig.9. Turbine position-pressure drop variation graph.

\section{Conclusions}

$5 \mathrm{~W}$ power is predicted for the operation of the turbo solenoid system. The average output power of the analysed turbines were calculated by using Equation 17 and are presented in Table 6 in order of magnitude.

Table 6. Mean produced power.

\begin{tabular}{|l|l|}
\hline Turbine Type & Mean Power [W] \\
\hline Lucid®-NACA0018 & 7.20 \\
\hline Gorlov 20-NACA0015 & 6.88 \\
\hline Gorlov 20-NACA0018 & 5.92 \\
\hline Darrieus-NACA0015 & 5.80 \\
\hline Darrieus-NACA0018 & 5.51 \\
\hline Darrieus-NACA0021 & 5.40 \\
\hline Gorlov 10-NACA0018 & 5.01 \\
\hline
\end{tabular}

One of the most important performance criteria of turbines is the power ratio (Eq. 18). The average power ratios for the analyzed turbines are presented in Table 7 in order of magnitude. 
Table 7. Mean power ratios.

\begin{tabular}{|l|l|}
\hline Turbine Type & Power Ratio \\
\hline Lucid®-NACA0018 & 0.0006485 \\
\hline Gorlov 20-NACA0015 & 0.0003572 \\
\hline Gorlov 20-NACA0018 & 0.0003076 \\
\hline Darrieus-NACA0015 & 0.0003010 \\
\hline Darrieus-NACA0018 & 0.0002860 \\
\hline Darrieus-NACA0021 & 0.0002806 \\
\hline Gorlov 10-NACA0018 & 0.0002604 \\
\hline
\end{tabular}

As a result of the comparisons made in Table 6 and Table 7, Gorlov turbine with $20^{\circ}$ twisted NACA0015 profile in terms of moment production and low pressure drop is considered as the best performing turbine.

\section{References}

[1]. Url < http://www.freedoniagroup.com/World-Industrial-Valves.html >, access date 26.02.2017.

[2]. J. Zanette, D. Imbault, A. Tourabi (2009). A design methodology for cross flow water turbines, Journal ofRenewable Energy 35 (2010) 997-1009

[3]. P.Marsh, D. Ranmuthugala, I. Penesis, G. Thomas (2014), Three-dimensional numerical simulations of straight-bladed vertical axis tidal turbines investigating power output, torque ripple and mounting forces, Journal ofRenewable Energy 83 (2015) 67 e77

[4]. Paraschivoiu I. Wind turbine design: with emphasis on Darrieus concept. Quebec, Canada: Polytechnic International Press; 2002

[5]. Scheurich F, Fletcher TM, Brown R. Simulating the aerodynamic performance and wake dynamics of a vertical-axis wind turbine. Journal of Wind Energy 2010;14:159e77

[6]. Marsh P, Ranmuthugala D, Penesis I, Thomas G. Performance predictions of a straight-bladed vertical axis turbine using doublemultiple streamtube and computational fluid dynamics. Journal of Ocean Technology 2013;8(1): 87e103.

[7]. Darrieus GJM. Turbine having its rotating shaft transverse to the flow of the current. US Patent number: US 1.835.018; 1931.

[8]. Gorlov AM. Helical turbine assembly operable under multidirectional fluid flow for power and propulsions systems. US Patent number: US 5.451.137; 1997.

[9]. Roderic, A. S. , Mark, R. C. , Edward, K., Igor, P., Greg, S. (2011), U.S. Patent No. 7959411 B2 Washington, DC: U.S. Patent and Trademark Office. 